\title{
GESTÃO DOCUMENTAL EM ESCOLAS ESTADUAIS DE MINAS GERAIS: UMA REVISÃO SISTEMÁTICA DE LITERATURA
}

\author{
DOCUMENT MANAGEMENT IN MINAS GERAIS \\ STATE SCHOOLS: A SYSTEMATIC LITERATURE \\ REVIEW
}

Josias Júlio de Araujoa

Elisângela Cristina Aganetteb

\begin{abstract}
RESUMO
Objetivo: Identificar estratégias metodológicas relacionadas à gestão documental, utilizadas para organização e recuperação de documentos, em escolas públicas da rede estadual de ensino de Minas Gerais. Metodologia: Para tal, apresenta-se como método a Revisão Sistemática de Literatura. Resultados: Ao final, foram selecionados 53 estudos que apresentaram relevância quanto às metodologias de gestão documental utilizadas para organização e recuperação de documentos. Conclusões: Identificou-se a necessidade de metodologias de GD, descritas de modo mais claro e específico, que apontem o passo-a passo para a implementação de metodologias de gestão documental nas instituições, uma vez que as mesmas têm utilizado métodos informais, e, por este motivo, apresenta falhas estruturais que podem trazer danos aos processos de gestão documental.
\end{abstract}

Descritores: Gestão Documental. Metodologia de Gestão Documental. Revisão Sistemática de Literatura. Escolas Públicas.

\section{INTRODUÇÃO}

A produção de documentos em meio físico ainda é uma prática cada vez mais frequente e abundante nas organizações, e estes, muitas vezes, tornam-

\footnotetext{
a Doutorando em Gestão e Organização do Conhecimento pela Universidade Federal de Minas Gerais (UFMG). E-mail: juliojosias@hotmail.com]

b Doutora em Ciência da Informação pela Universidade Federal de Minas Gerais (UFMG). Docente da Escola de Ciência da Informação (ECI/UFMG). E-mail: elisangelaaganette@gmail.com
} 
se os únicos registros documentais de processos e atividades realizadas em uma instituição e desse modo precisam ser devidamente organizados para acesso e recuperação, uma vez que podem ser solicitados como fonte de comprovação ou evidência de algum processo. Para garantir a confiabilidade e o acesso futuro aos documentos em meio físico é essencial a implementação da Gestão Documental (GD), seja por meio de metodologias, práticas, normas ou procedimentos.

No entanto, implementar tais metodologias, práticas, normas ou procedimentos de GD não é uma tarefa fácil e corriqueira. Percebe-se que os gestores têm percebido a real importância de se pensar sobre a GD nas instituições. Ao se mencionar as instituições de ensino, especificamente as escolas públicas da rede estadual de ensino de Minas Gerais, contexto do presente artigo, a situação é preocupante e urgente, ao se pensar na gestão documental, que na maioria das vezes é simplesmente ignorada. Tais instituições precisam se adequar, se modernizarem e principalmente definirem uma metodologia de GD que as orientem quanto à implementação da gestão de seus acervos documentais. Tal pressuposto é colocado pelos presentes autores, a partir da vivência profissional dos mesmos.

Na maior parte dos casos, os acervos documentais destas escolas ficam sob a responsabilidade dos servidores técnicos administrativos que atuam na escola. Não existindo uma padronização no modo de se organizar os referidos documentos. Vale ressaltar que essas instituições são órgãos públicos e, portanto, devem seguir a legislação que trata da gestão do seu acervo documental bem como a preservação do mesmo.

Os documentos que compõem o acervo dessas escolas públicas contêm informações de elevada importância e valor legal. Desse modo tais documentos precisam de tratamento adequado, com base em estratégias planejadas que possam conduzir ao correto armazenamento e preservação dos conteúdos informacionais (SANTOS; FLORES, 2015, p. 68), bem como assegurar o acesso sempre que necessário a esses instrumentos, conforme previsto na Constituição da República Federativa do Brasil (BRASIL, 1988) e demais instrumentos legais. 
Evidencia-se assim, a necessidade de se adotar uma metodologia de GD, que possibilitará maior segurança e confiabilidade nos processos de GD implementados por essas escolas. O presente artigo tem como objetivo identificar, por meio de uma Revisão Sistemática de Literatura (RSL), experiências de implementação de metodologias, práticas e ou procedimentos de Gestão Documental. Justifica-se a sua relevância por sintetizar conteúdos essenciais para a orientação do processo de formulação e desenvolvimento das ações de GD, práticas ainda incipientes no que tange a sua formalização.

Ressalta-se que este artigo foi desenvolvido a partir de resultados parciais obtidos em uma pesquisa de doutorado, em andamento, com a qual se busca investigar e analisar ações de operacionalização de Gestão Documental em instituições de ensino públicas.

As demais seções do artigo estão organizadas da seguinte maneira: a seção 2 refere-se ao referencial teórico utilizado para definir e fundamentar os principais conceitos relacionados ao objeto de estudo, tais como: gestão documental e metodologias de gestão documental. A seção 3 , refere-se ao método utilizado para se alcançar o objetivo proposto, a Revisão Sistemática de Literatura (RSL). A seção 4 apresenta os resultados e, finalmente, a seção 5 as considerações finais.

\section{GESTÃO DOCUMENTAL}

Os documentos são originados das atividades rotineiras dos indivíduos ou não, a eles podem ser atribuídos valores além das finalidades pelas quais foram criados, tais como valores probatórios, informacionais, de pesquisa e histórico institucional (FONSECA, 2002). E que segundo Ortega (2010, p. 17) "o documento pode ser utilizado como um instrumento para promover a circulação social do conhecimento além daqueles objetivos já instituídos por ele no momento da sua criação". Já Schellenberg (2007) caracteriza "documento" quanto ao suporte, formato, gênero, espécie e tipo:

Suporte - diz respeito ao material sobre o qual as informações são registradas e é a base física dos documentos. Exemplo: fita magnética, filme de nitrato, papel. Formato - configuração física 
de um suporte, de acordo com a natureza e o modo como foi confeccionado. Exemplo: caderno, cartaz, dispositivo, folha, mapa, planta, rolo de filme, etc. Gênero - configuração que assume um documento de acordo com o sistema de signos utilizado na comunicação de seu conteúdo. Exemplo: documentação audiovisual, (fotos) fonográfica (representação gráfica das palavras) iconográfica (imagens). Espécie configura que um documento de acordo com a disposição e a natureza das informações nele contidas. Exemplo: boletim, certidão, declaração, relatório, ata. Tipo - configuração que assume uma espécie documental, de acordo com a atividade que a gerou. Exemplo: boletim de ocorrência, boletim de frequência e rendimento escolar, relatório técnico, etc (SCHELLENBERG, 2007, p. 46).

A Gestão Documental (GD) possui como epicentro os Estados Unidos, que a denominaram como records management, e tem como objetivo organizar e sistematizar os procedimentos técnicos na tratativa e gestão dos documentos correntes e intermediários, visando assim a eliminação ou recolhimento em arquivo permanente. A implementação dos procedimentos de GD foi um marco histórico para a Arquivologia (RONDINELLI, 2005). Segundo Jardim (2005), a GD pode ser compreendida como:

Uma operação arquivística que visa reduzir seletivamente as proporções manipuláveis da massa de documentos, que é característica da civilização moderna, de forma a conservar permanentemente os que têm um valor cultural futuro sem menosprezar a integridade substantiva da massa documental para efeitos de pesquisa (JARDIM, 2005, p. 28).

Nesse direcionamento Ponjuán (2004), à considera como um processo administrativo que permite analisar e controlar sistematicamente ao longo do seu ciclo de vida o documento criado, recebido, mantido e utilizado na organização, relacionadas à missão, objetivos e operações. O autor salienta que tal processo garante que se mantenha as informações em um formato que permite o acesso em tempo útil, exigindo que se implementem práticas e procedimentos para gestão de cada fase e uso desta informação registrada, uma vez que se trata de evidências das atividades e operações das instituições. E Jardim (2005) ressalta que tal processo administrativo visa proteger o acervo documental institucional bem como gerar informações e dados relevantes para que elas exerçam suas atividades administrativas ao longo dos tempos com maior eficiência nas suas ações. 
Couture e Rousseau (1998) destacam que os procedimentos de GD são relevantes no contexto institucional, uma vez que tais documentos produzidos, recebidos e acumulados nos diversos setores das organizações são mantidos, durante o ciclo de vida, em seus arquivos por período que corresponde ao tempo em que as informações neles contidas sejam necessárias àquela instituição ou atenda às necessidades dos usuários. Dessa forma, torna-se essencial e de extrema necessidade a implementação de práticas, metodologias e procedimentos no contexto institucional, uma vez que, ela auxilia e facilita a realização dos procedimentos gerenciais do acervo documental. Os autores relatam ainda, que a GD é um processo de controle, de sistematização e tratamento dos documentos, que pode permitir o seu armazenamento, recuperação e disseminação de acordo com as necessidades das instituições.

Assim a GD pode ser compreendida como um conjunto de práticas metodológicas que possibilitam conhecer, entender e otimizar os fluxos documentais e informacionais (LOPES,1996) possibilitando eficácia nos processos de gestão dos documentos institucionais.

\section{METODOLOGIA DE GESTÃO DOCUMENTAL}

Entender a definição e as características do conceito "metodologia" é premissa fundamental para este estudo, uma vez que tal entendimento foi de fundamental importância para análise dos dados desta RSL. A terminologia utilizada (metodologia de GD) às vezes pode não ser o que se aplica.

Assim, neste artigo, utiliza-se a definição de metodologia, apresentada por Demo (1995), que a define como sendo um conjunto de procedimentos e regras utilizadas por determinado método e possui como intenção a discussão sobre a problemática da pesquisa por meio do debate teórico, buscando criticamente maneiras de se fazer ciência.

No que se refere à metodologia de Gestão Documental, Elias (2012) define como sendo as etapas e o caminho percorrido para atingir determinado objetivo relacionado ao gerenciamento documental. É a sistematização dos métodos utilizados para a organização e gerenciamento do acervo documental, utilizando-se de métodos e técnicas específicas. Assim, a metodologia de 
Gestão Documental estabelece também relação entre as etapas e o objetivo determinado (ALMEIDA; VITORIANO, 2018). A metodologia de GD pode ser compreendida como o conjunto de técnicas e procedimentos que possibilita a instituição gerenciar todo o processo de gestão nas fases de produção, uso, organização, armazenamento ou eliminação (TEIXEIRA; AGANETTE; ALMEIDA, 2015).

Diante das definições e estudos analisados, apresenta-se, a seguir as características essenciais de uma Metodologia de Gestão Documental: a) define o caminho, o método e as etapas necessárias para realização das tarefas relacionadas à $\mathrm{GD}$; b) define as ferramentas necessárias para realização das tarefas propostas; c) gera novos conhecimentos; d) sistematiza práticas de gestão; e) responde a questionamentos; f) apresenta diretrizes relacionadas à GD; g) identifica as relações dos documentos gerados ou armazenados pelas instituições; h) é flexível e permite a inclusão de novas etapas, o monitoramento das ações realizadas e o refinamento dos processos utilizados e por fim, i) apresenta instruções de trabalho para facilitar a operacionalização do processo.

\section{MÉTODO: RSL}

Para realização desta investigação foi utilizado o método da Revisão Sistemática de Literatura (RSL), proposto por Biolchini (2005). Trata-se de uma estratégia de representação da literatura relacionada ao tema proposto e abrange de modo imparcial os estudos científicos e ainda atribui validade científica aos mesmos (EVANS; PEARSON, 2001, p. 42). Ainda segundo os autores, a RSL é um procedimento de seleção de referências utilizando critérios explícitos e replicáveis, com o objetivo de minimizar o risco de viés, atribuindo validade científica à discussão produzida.

De acordo com Biolchini et al. (2005), a RSL é conduzida por um planejamento, por um protocolo definido previamente e em seguida por 6 (seis) etapas, sendo elas: Etapa 1: Construção da pergunta; Etapa 2:Construção da expressão de busca; Etapa 3: Definição das bases de dados; Etapa 4:Critérios de elegibilidade dos documentos; Etapa 5: Seleção dos documentos e, Etapa 6: Análises quantitativa e qualitativa dos dados. 
No contexto deste artigo, a presente RSL buscou responder à seguinte questão de pesquisa: quais metodologias, práticas e ou procedimentos de Gestão Documental as Escolas Públicas do Estado de Minas Gerais (EEMG) adotam?

Utilizou-se, como termos de busca, os seguintes conceitos: "Gestão Documental"; "Metodologias de Gestão Documental", "Sistematização de documentos" e "Escola Pública". O uso dos termos compostos, incluído entre aspas, se justifica, pois facilitou no momento da restrição e recuperação de conteúdos que abordassem exatamente as expressões propostas. Salienta-se que a maioria das RSL publicadas, consideram o uso da expressão de busca no idioma inglês. Assim, este artigo também adotou esta prática.

Inicialmente realizou-se um levantamento das bases de dados, na plataforma de busca da Coordenação de Aperfeiçoamento de Pessoal de Nível Superior (CAPES), considerando conteúdos relacionados à Ciência da informação $(\mathrm{Cl})$ e suas subáreas. Tal levantamento gerou um total de 89 bases de dados, todas relacionadas à Ciência da informação $(\mathrm{Cl})$ e suas subáreas. Diante do volume representativo de bases, o que inviabilizaria o estudo, naquele momento, fez-se necessário um recorte, que considerou as áreas de pesquisa dos autores deste artigo, e principalmente a representatividade das referidas bases de dados que oferecem conteúdos relevantes à área da $\mathrm{Cl}$. Feito o recorte, selecionou-se 6 (seis bases), sendo elas: 1) Information Science and Technology Abstracts (ISTA), 2) Library and Information Science Abstracts (LISA), 3) Library, Information Science \& Technology Abstracts (LISTA), 4) Scopus, 5) Scientific Electronic Library online (SCIELO) e, 6) Web of Science (WOS).

Como critério de elegibilidade principal, adotou-se o estudo científico publicado em periódicos científicos, sendo este um item documental preferencial e primário; como item documental secundário, considerou-se teses, dissertações e estudos apresentados em eventos científicos. Quanto aos critérios de inclusão e exclusão, tem-se o Quadro 1 a seguir. 
Quadro 1 - Critérios de inclusão e exclusão

\begin{tabular}{|l|l|}
\hline \multicolumn{1}{|c|}{ Critérios de inclusão } & \multicolumn{1}{c|}{ Critérios de exclusão } \\
\hline $\begin{array}{l}\text { Publicações sem recorte de } \\
\text { temporalidade. }\end{array}$ & $\begin{array}{l}\text { Publicações apresentadas no formato de pôster, } \\
\text { palestras, workshop, resumos, resenhas. }\end{array}$ \\
\hline $\begin{array}{l}\text { Publicações em um dos idiomas } \\
\text { definidos. }\end{array}$ & $\begin{array}{l}\text { Publicações que não mencionam em seu } \\
\text { conteúdo práticas, metodologias ou } \\
\text { procedimentos de Gestão Documental. }\end{array}$ \\
\hline Publicações de caráter científico. & $\begin{array}{l}\text { Publicações que apenas citam GD, mas não } \\
\text { conceituam. }\end{array}$ \\
\hline $\begin{array}{l}\text { Publicações disponíveis integralmente } \\
\text { para leitura com ou sem ônus } \\
\text { financeiro. }\end{array}$ & Publicações fora do contexto da revisão. \\
\hline $\begin{array}{l}\text { Publicações relacionadas à Gestão } \\
\text { Documental. }\end{array}$ & $\begin{array}{l}\text { Publicações que apresentem idiomas diferentes } \\
\text { daqueles definidos, ou seja, do Inglês e do } \\
\text { Português. }\end{array}$ \\
\hline $\begin{array}{l}\text { Publicações que indiquem instrumentos } \\
\text { práticos, relacionados às práticas, } \\
\text { metodologias ou procedimentos de GD. }\end{array}$ & $\begin{array}{l}\text { Publicações que não apresentem caráter } \\
\text { científico, }\end{array}$ \\
\cline { 2 - 3 } & $\begin{array}{l}\text { Publicações que não apresentem relação com a } \\
\text { temática de GD. }\end{array}$ \\
\cline { 2 - 3 } & $\begin{array}{l}\text { Publicações que não mencionem as expressões } \\
\text { de busca definidas no título ou no resumo. }\end{array}$ \\
\hline
\end{tabular}

Fonte: Elaborado pelos autores

O processo de seleção dos documentos foi realizado durante os meses de março a maio de 2020, por meio da opção "busca avançada" disponível nas bases de dados elencadas. Os conteúdos dispostos nos campos título e resumo foram selecionados. Salienta-se que este modo de seleção de conteúdo auxiliou na padronização da busca em todas as bases de dados, e na recuperação de documentos que provavelmente tratam de Gestão Documental, uma vez que a expressão foi incluída nos metadados mais representativos do conteúdo do documento.

A leitura sistematizada e as devidas análises foram realizadas nas seções constantes nos estudos selecionados tais como: resumo, introdução, considerações finais e/ou conclusão. A esse respeito, Lopes (1996, p. 16) esclarece que, "quando o indexador se depara com grande quantitativo de documentos para a extração de conteúdo, deve-se focar a atenção nas seções que representam o máximo de informações". 


\section{RESULTADOS}

Para a análise, levou-se em consideração as características dos estudos, dos autores e das instituições bem como a metodologia de GD utilizada em cada um dos estudos recuperados por meio da RSL.

\subsection{Estudos Selecionados: Caracterização}

A busca nas citadas bases de dados, após aplicação do protocolo de RSL, retornou um total de 3.320 publicações, sendo 123 deles repetidos, ou que se referiam a notas de editores, notícias, resenhas, papers e documentos utilizados em apresentação de eventos. Restando um total de 3.197 estudos. Destes, foram selecionados 53 estudos, de acordo com os critérios de elegibilidade préestabelecidos, e que apresentaram relevância para compor o portfólio bibliográfico desta RSL. Os 53 estudos foram selecionados para uma análise exaustiva e extração de informações, conforme apresentado na Tabela 1 a seguir.

\begin{tabular}{lcc}
\multicolumn{2}{c}{ Tabela 1 - Estudos selecionados para análise preliminar } \\
\hline \multicolumn{1}{c}{ Base } & Estudos Descartados & Estudos Selecionados \\
& & \\
\hline ISTA & 56 & 3 \\
LISA & 254 & 11 \\
LISTA & 108 & 4 \\
SCOPUS & 2100 & 4 \\
SCIELO & 14 & 1 \\
WOS & 612 & 30 \\
\hline TOTAL & $\mathbf{3 1 4 4}$ & $\mathbf{5 3}$ \\
\hline
\end{tabular}

Fonte: Elaborado pelos autores

A leitura e análise dos títulos e resumos dos 53 estudos selecionados evidenciou aspectos e características de metodologias de GD, aplicadas em distintos contextos, tais como: i) Bibliotecas pública, acadêmica e digital, ii) Hospital; iii) Escola pública e privada, iv) Universidade pública, v) Redes sociais, vi) Empresa Privada e, vii) Arquivo Pessoal. No que tange às análises quantitativa e qualitativa, pode-se verificar como a temática gestão documental vem sendo tratada a partir da literatura científica, em âmbito nacional e internacional.

A partir dos referidos estudos selecionados, pode-se verificar o ano de publicação, país e autores dos mesmos. Os 53 estudos científicos selecionados 
correspondem a $1,6 \%$ da totalidade de estudos recuperados inicialmente, de um total de 3.320. Sendo que a maior parte desses estudos estão disponíveis na base de dados WoS.

Por meio da análise dos referidos estudos, foi possível identificar 7 (sete) contextos de aplicação das referidas metodologias de GD, tais como: Bibliotecas pública, acadêmica digital (25 estudos), Hospital (6 estudos); Escola pública e privada (12 estudos), Universidade pública (3 estudos), Redes sociais (5 estudos), Empresa Privada (1 estudo) e Arquivo Pessoal (1 estudo). O Apêndice $A$, apresenta a relação de todos os estudos selecionados de acordo com o ano de publicação, autor e contexto de aplicação.

Ressalta-se que dos estudos selecionados, 52 deles foram publicados em idioma inglês, e apenas um em idioma português (base de dados Scielo). Quanto aos anos de publicação dos estudos selecionados. $O$ ano de 2015 foi o que teve maior número de publicações, em relação aos anos anteriores, um total de 10 estudos em relação à metodologia de GD. Isso, pode estar associado ao crescimento do volume de informações produzidas e compartilhadas, facilitada pelas redes sociais e pelo fato da informação ser reconhecida como bem patrimonial. No ano de 2019 foram 9 (nove) estudos publicados, e isto pode estar relacionado ao número expressivo de cursos de especialização que tratam de aspectos relacionados a GD oferecidos em nível Stricto Sensu pelas universidades.

O Gráfico 1 a seguir, evidencia o número de estudos publicados, do ano de 1993 a 2019.

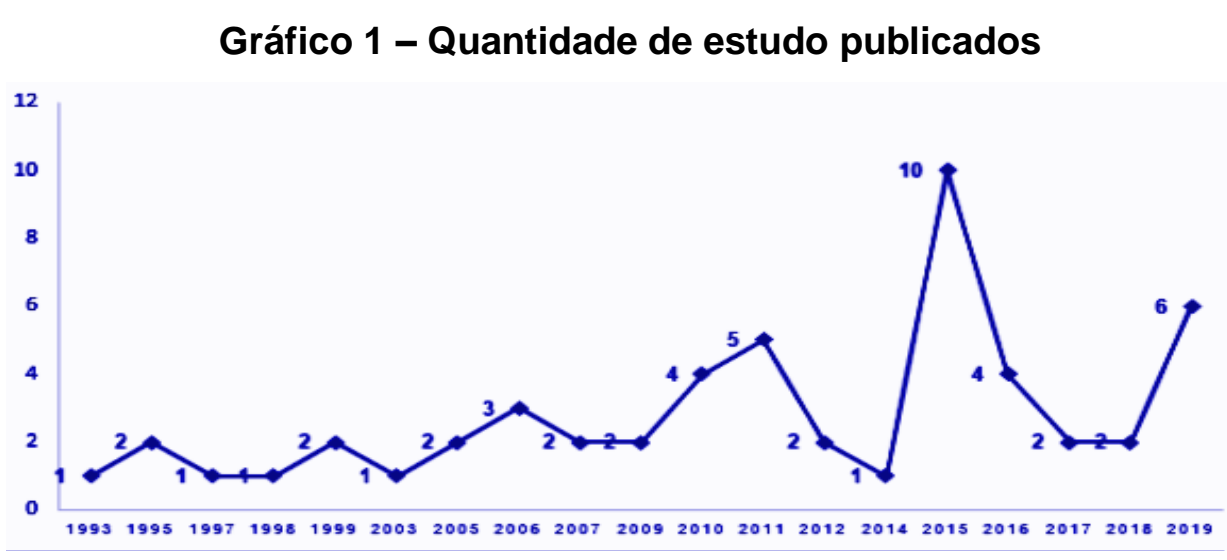

Fonte: Araújo e Aganette (2021) 
No que se refere à publicação por países, no que tange à temática metodologia de GD, a presente RSL evidenciou que os EUA, lidera o ranking, com $37,74 \%$, em seguida, tem-se o Brasil, com $11,32 \%$ das publicações. $O$ Gráfico 2, a seguir, mostra a relação de países com alguma publicação relacionada a temática.

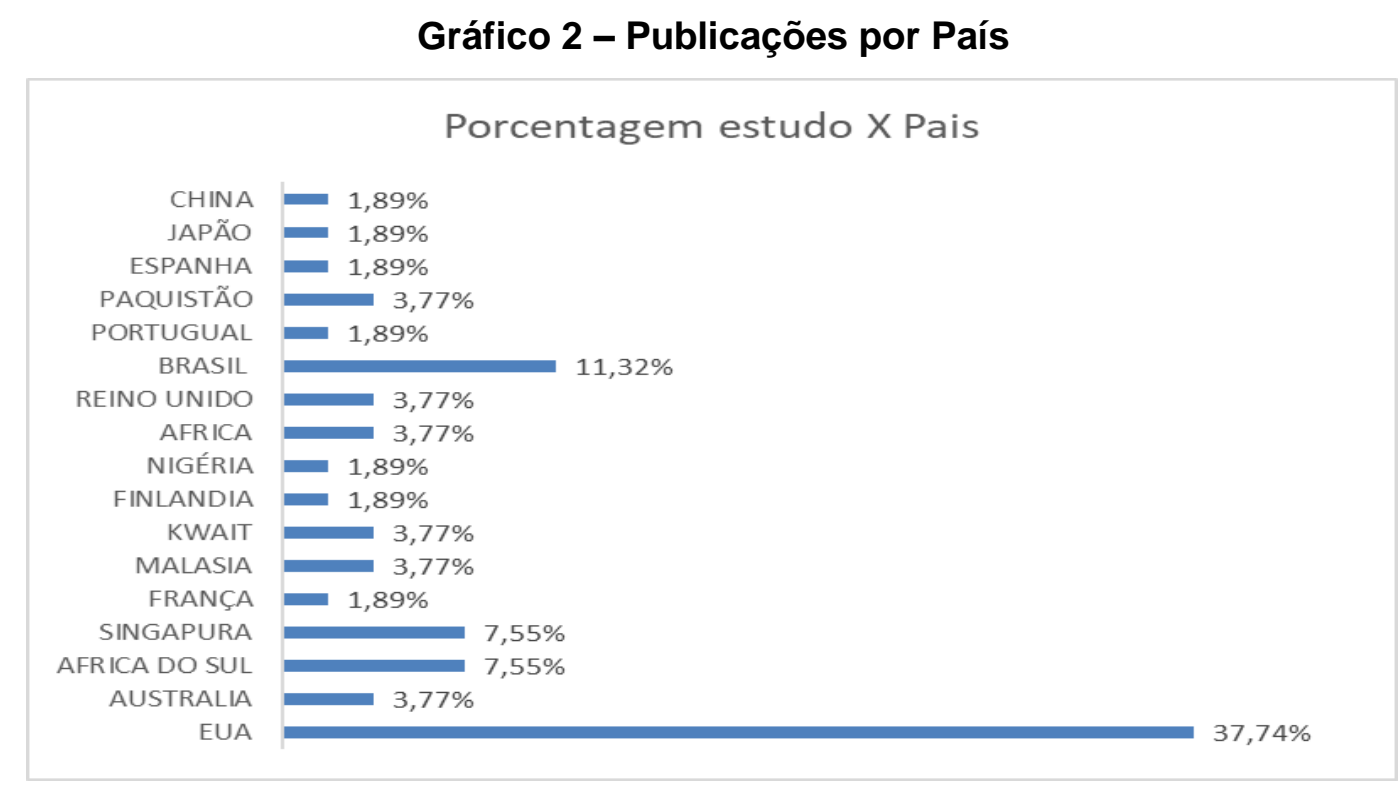

Fonte: Araújo e Aganette (2021)

\subsection{Estudos Selecionados: Descrição e Análises}

Ressalta-se que, este artigo, não teve como foco, analisar se o que os autores dos referidos estudos, nomeiam ou consideram como metodologia de gestão documental, está de acordo com a seção 3, proposta pelos autores deste artigo, em que se define e caracteriza uma metodologia de GD.

O Quadro 2 a seguir, apresenta de modo sucinto, o contexto, os autores dos estudos analisados e a descrição das principais práticas e metodologias de GD identificadas. Além disso, os estudos estão descritos no "apêndice A relação dos estudos selecionados por contexto de aplicação". 
Quadro 2 - Descrição das metodologias de GD

\begin{tabular}{|c|c|c|}
\hline Contexto & Autores & Descrição \\
\hline Escola pública & CHU, KaiWing & $\begin{array}{l}\text { Chu (2016) descreve o processo para a } \\
\text { implementação de procedimentos para o } \\
\text { gerenciamento dos documentos pedagógicos } \\
\text { produzidos por professores de uma escola } \\
\text { japonesa. E para isso são indicadas etapas } \\
\text { sendo elas: i) roteiro; ii) padronização; iii) } \\
\text { validação, iv) controle de acesso; v) uso de } \\
\text { softwares de gestão e, vi) plano de preservação } \\
\text { documental. A metodologia proposta traz } \\
\text { detalhamento de todas essas etapas e } \\
\text { apresenta os procedimentos para possíveis } \\
\text { ajustes quando necessários. A proposta } \\
\text { apresentada pelo autor foi testada por meio de } \\
\text { um estudo de caso, onde foi possível verificar } \\
\text { todas as etapas propostas. O autor apresenta } \\
\text { um breve roteiro contendo todas as etapas e } \\
\text { uma breve descrição de cada uma delas. O } \\
\text { roteiro apresenta além das etapas aspectos } \\
\text { relacionados a treinamento e uso de ferramentas } \\
\text { tecnológicas nos procedimentos de gestão. Chu } \\
\text { (2016) relata que a complexidade dos } \\
\text { documentos que são produzidos nos setores } \\
\text { internos das escolas requer do gestor aplicação } \\
\text { de técnicas adequadas e pré-definidas em } \\
\text { planos de gestão do acervo documental. }\end{array}$ \\
\hline $\begin{array}{l}\text { Bibliotecas } \\
\text { Pública, Digital, } \\
\text { e acadêmica }\end{array}$ & 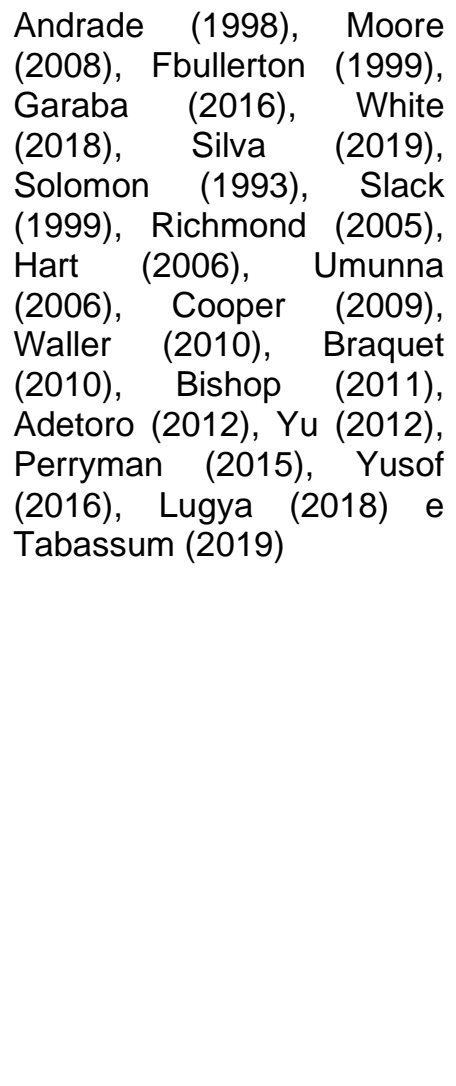 & $\begin{array}{l}\text { A metodologia proposta pelos autores é } \\
\text { composta por } 7 \text { (sete) etapas, sendo elas: i) } \\
\text { entrevistas; ii) padronização dos procedimentos; } \\
\text { iii) suporte técnico aos usuários; iv) } \\
\text { tutoria/treinamento; v) preservação do acervo; vi) } \\
\text { ajustes necessários e, vii) controle. Eles } \\
\text { ressaltam que para iniciar as etapas indicadas é } \\
\text { necessária a realização de reuniões e } \\
\text { entrevistas com os responsáveis pelo } \\
\text { gerenciamento do acervo institucional. Moore } \\
\text { (2008) cita que as reuniões têm por objetivo } \\
\text { definir o papel de cada um no processo de } \\
\text { gestão. Os estudos indicam que a implantação } \\
\text { de novos procedimentos requer que todos que } \\
\text { atuam na instituição sejam envolvidos e } \\
\text { conheçam o processo. Garaba (2016) e White } \\
\text { (2018) propõem a realização de um ciclo de } \\
\text { melhoria contínua nos procedimentos de gestão } \\
\text { e assim aprimorar as ações já instituídas. White } \\
\text { (2018) relata que as instituições devem avaliar } \\
\text { os recursos disponíveis, principalmente os } \\
\text { recursos digitais. Solomon (1993), Slack (1999), } \\
\text { Richmond (2005), Waller (2010), Braquet (2010), } \\
\text { Bishop (2011), Adetoro (2012), Yu (2012), } \\
\text { Perryman (2015) e Yusof (2016) propõem } \\
\text { inicialmente levantamento preliminar do acervo } \\
\text { documental e uma catalogação. Para Braquet }\end{array}$ \\
\hline
\end{tabular}




\begin{tabular}{|c|c|c|}
\hline Contexto & Autores & Descrição \\
\hline & & $\begin{array}{l}\text { (2010) em um projeto que envolve a gestão } \\
\text { documental, o controle do acesso aos } \\
\text { documentos é uma das etapas essenciais e } \\
\text { necessárias, pois a mesma visa proteger e } \\
\text { preservar o acervo documental da instituição. }\end{array}$ \\
\hline Hospitais & $\begin{array}{l}\text { LaVenture (1997), Ruffin } \\
\text { (2005), Rachel (2007), Budd } \\
\text { (2015), Marouf (2015), } \\
\text { Rodriguez (2016) e Melese } \\
\text { (2019) }\end{array}$ & $\begin{array}{l}\text { Os autores propõem a implementação de uma } \\
\text { metodologia dividida em } 6 \text { (seis) etapas sendo } \\
\text { elas: i) levantamento da estrutura } \\
\text { organizacional; ii) levantamento da produção } \\
\text { documental; iii) uso dos documentos; iv) plano } \\
\text { de classificação; v) procedimentos de descarte } \\
\text { dos documentos e, vi) infraestrutura para } \\
\text { armazenamento dos documentos. Os autores } \\
\text { destacam a importância de elaboração de um } \\
\text { planejamento periódico quanto ao tratamento } \\
\text { dos documentos através da elaboração de plano } \\
\text { de descarte de documentos que possa orientar } \\
\text { os usuários. Além disso, eles indicam a } \\
\text { padronização dos procedimentos de gestão em } \\
\text { todos os setores da instituição, possibilitando } \\
\text { assim uniformização das ações facilitando assim } \\
\text { os procedimentos de organização e } \\
\text { recuperação. Ruffin (2005) e Rachel (2007) } \\
\text { salientam a importância de realização de } \\
\text { treinamentos periódicos com os usuários e a } \\
\text { equipe de gestão. De forma geral os autores } \\
\text { propõem que seja elaborado um planejamento } \\
\text { prévio que envolva essas ações e outras que } \\
\text { possam colaborar com as práticas } \\
\text { metodológicas adotadas pelas instituições. }\end{array}$ \\
\hline $\begin{array}{l}\text { Empresas } \\
\text { privadas }\end{array}$ & Marouf (2015) & $\begin{array}{l}\text { A metodologia apresentada pelo autor foi o } \\
\text { estudo de caso, o que possibilitou conhecer o } \\
\text { contexto de aplicação das etapas propostas. O } \\
\text { autor propõe um guia para facilitar a implantação } \\
\text { procedimentos metodológicos que foram } \\
\text { divididos em etapas, sendo elas: i) } \\
\text { planejamento; ii) avaliação; iii) classificação; iv) } \\
\text { eliminação; v) ajustes; vi) controle; vii) acesso e, } \\
\text { viii) o treinamento adequado dos usuários. O } \\
\text { autor evidencia que o planejamento é o ponto de } \\
\text { partida para a implementação de novas práticas }\end{array}$ \\
\hline
\end{tabular}




\begin{tabular}{|c|c|c|}
\hline Contexto & Autores & Descrição \\
\hline & & $\begin{array}{l}\text { no contexto de gestão. Já em um segundo } \\
\text { momento deverá ser realizada a avaliação } \\
\text { documental, o que possibilitará definir } \\
\text { estratégias para realizar as ações. Além disso, } \\
\text { os gestores devem adotar diretrizes que possam } \\
\text { complementar aquelas já utilizadas na } \\
\text { instituição. }\end{array}$ \\
\hline Redes Sociais & $\begin{array}{l}\text { Slone (2003), Bowler } \\
\text { (2011), Khoo (2014), Talip } \\
\text { (2015) e Aula (2015) }\end{array}$ & $\begin{array}{l}\text { Os autores indicam que inicialmente é essencial } \\
\text { conhecer os conteúdos dos documentos e assim } \\
\text { pode classificá-los de acordo com sua função. } \\
\text { Além disso, deve-se utilizar tecnologias } \\
\text { adequadas para o gerenciamento do acervo. } \\
\text { Assim a metodologia proposta por esses autores } \\
\text { é definida em } 4 \text { (quatro) etapas sendo elas: i) } \\
\text { avaliação de conteúdo; ii) classificação; iii) } \\
\text { armazenamento; iv) controle; v) preservação e, } \\
\text { iv) uso de ferramentas adequadas. Após a } \\
\text { realização de cada etapa é realizada a validação } \\
\text { final, descrevendo a finalidade, as atividades } \\
\text { realizadas, as ferramentas e técnicas utilizadas. } \\
\text { Bowler (2011) cita que os documentos de } \\
\text { formato semelhantes devem ser destinados a } \\
\text { um único local, evitando assim que os mesmos } \\
\text { ocupem vários espaços na instituição, trazendo } \\
\text { assim desorganização no processo de gestão. } \\
\text { Khoo (2014) e Talip (2015) citam que a } \\
\text { racionalização do fluxo documental possibilita } \\
\text { seu controle, acesso e autenticidade. Talip } \\
\text { (2015) relata que as instituições devem explorar } \\
\text { as novas tecnologias emergentes nos processos } \\
\text { de gerenciamento do acervo, buscando assim } \\
\text { qualidade nos processos de gerenciamento. } \\
\text { Além disso há a necessidade de implementar } \\
\text { uma política de gestão documental interna, } \\
\text { buscando normatizar os procedimentos } \\
\text { relacionados à gestão documental. }\end{array}$ \\
\hline $\begin{array}{l}\text { Universidade } \\
\text { Pública }\end{array}$ & $\begin{array}{l}\text { Ritzo (2009), Jacso (2010) e } \\
\text { Chang (2015) }\end{array}$ & $\begin{array}{l}\text { A metodologia apresentada por Ritzo (2009), } \\
\text { Jacso (2010) e Chang (2015) são definidas em } 5 \\
\text { (cinco) etapas sendo elas: i) identificação, ii) } \\
\text { avaliação, iii) estado de preservação, iv) acesso } \\
\text { e controle e, v) plano de eliminação. As etapas } \\
\text { foram testadas por meio de um estudo de caso. } \\
\text { Após a realização de todas as etapas foi } \\
\text { realizada a validação de cada uma delas. Os } \\
\text { autores destacam que a primeira fase da } \\
\text { metodologia é aquela que o gestor realiza a } \\
\text { avaliação e descrição dos documentos e indica } \\
\text { o estado de preservação do documento. Jacso } \\
\text { (2010) propõe inicialmente a catalogação do } \\
\text { acervo documental visando assim controle do } \\
\text { acervo documental o que possibilitará } \\
\text { procedimentos de recuperação mais eficientes. } \\
\text { Chang (2015) destaca a importância do }\end{array}$ \\
\hline
\end{tabular}




\begin{tabular}{|l|l|l|}
\hline Contexto & \multicolumn{1}{|c|}{ Autores } & \multicolumn{1}{|c|}{ Descrição } \\
\hline & Latham (2011) & $\begin{array}{l}\text { monitoramento do acervo documental. Os } \\
\text { autores ainda ressaltam a importância do } \\
\text { refinamento dos procedimentos buscando assim } \\
\text { qualidade e segurança nos mesmos. }\end{array}$ \\
\hline $\begin{array}{l}\text { Arquivo } \\
\text { Pessoal }\end{array}$ & $\begin{array}{l}\text { A metodologia utilizada por Latham (2011) } \\
\text { propõe a melhoria nos processos de gestão e } \\
\text { para isso foi implementado o estudo de caso, o } \\
\text { que possibilita conhecer o contexto de aplicação } \\
\text { eas etapas propostas. Oautor propõe 4 (quatro) } \\
\text { etapas para a implementação dos } \\
\text { procedimentos, sendo elas: i) avaliação, ii) } \\
\text { catalogação; iii) padronização e, iv) eliminação. } \\
\text { Essas etapas foram detalhadamente testadas e } \\
\text { descritas quanto às suas atividades e seus } \\
\text { resultados. Além dessas etapas o autor relata } \\
\text { que o constante aprimoramento se torna } \\
\text { necessário, buscando ajustes quando } \\
\text { necessários. }\end{array}$ \\
\hline
\end{tabular}

Fonte: Elaborado pelos autores

\section{CONSIDERAÇÕES FINAIS}

A presente RSL, evidenciou que há um campo profícuo de estudos e investigações em relação à gestão documental, suas práticas e metodologias direcionados as instituições escolares, principalmente aquelas públicas. Existem várias lacunas que precisam ser investigadas, para melhoria do uso e da aplicação da gestão documental nessas instituições. Além disso, o resultado da presente revisão de literatura evidenciou a reduzida exploração do termo metodologia de GD e dos conteúdos a ele associados na literatura científica.

Retomando a questão de pesquisa desta RSL, que buscou identificar quais metodologias, práticas e ou procedimentos de Gestão Documental as Escolas Públicas do Estado de Minas Gerais (EEMG) adotam, identificou-se a necessidade de metodologias de GD, descritas de modo mais claro e específico, que apontem de maneira padronizada o passo-a passo para a implementação de metodologias de GD nessas instituições, uma vez que as mesmas têm utilizado métodos informais, e, por este motivo, apresenta falhas estruturais que podem trazer danos à organização dos documentos bem como aos procedimentos de recuperação dos mesmos. 
Entretanto, ressalta-se que o baixo índice na recuperação de estudos que tratam de metodologia de GD não pode ser definido como ausência de uso e aplicação da mesma, considerando, que as instituições e profissionais podem optar por não relatarem suas experiências em trabalhos científicos, não publicizando ou circulando-as apenas no contexto interno da instituição e ainda, deve-se considerar que práticas que não obtiveram sucesso em sua realização, em grande parte das vezes, não são relatadas e muito menos publicadas.

Acredita-se que os documentos recuperados e analisados fornecem importantes subsídios para a compreensão dos processos e podem ser consultados na íntegra pelos interessados na temática. Diante disso, apresentase como sugestões para trabalhos futuros a aplicação da técnica de RSL para identificação de processos específicos de gestão documental, tais como: tratamento, organização, acesso e recuperação.

\section{REFERÊNCIAS}

ALMEIDA, Maria Fabiana Izídio de; VITORIANO, Marcia Cristina de Carvalho Pazin. Diagnóstico de arquivos e mapeamento da informação: interlocução da gestão documental com a gestão da informação. Em Questão, Porto Alegre, v. 24, n. 3, p. 68-95, mar. 2018. Disponível em: https://seer.ufrgs.br/EmQuestao/article/view/75830. Acesso em: 20 jul. 2021.

ARAÚJO, Josias Júlio de; AGANETTE, Elisângela Cristina. Gestão Documental do Dossiê Funcional de Servidores de Escolas Públicas. Revista Informação na Sociedade Contemporânea, Natal, v. 5, p. 1-25, dez. 2021.

BIOLCHINI, Jorge; MIAN, Paula Gomes; NATALI, Ana Candida Cruz; TRAVASSOS, Guilherme Horta. Systematic review in software engineering. Technical Report ES, Rio de Janeiro, v. 679, n. 5, p. 1-30, 2005. Disponível em: https://www.cos.ufr..br/uploadfile/es67905.pdf. Acesso em: 30 jan. 2021.

BRASIL. Constituição da República Federativa do Brasil. Brasília: Senado Federal, 1988.

COUTURE, Carol; ROUSSEAU, Jean-Yves. Os fundamentos da disciplina arquivística. Lisboa: Publicações Dom Quixote, 1998.

DEMO, Pedro. Metodologia Científica em Ciências Sociais. 3. ed. São Paulo: Atlas, 1995. 
ELIAS, Ezmir Dippe. Gerenciamento eletrônico de documentos (GED): aplicação na Universidade Federal de Santa Catarina. ÁGORA, Florianópolis, v. 22, n. 45, p. 15-30, jan./jun. 2012. Disponível em:

https://brapci.inf.br/index.php/res/download/48043. Acesso em: 20 jul. 2021.

EVANS, David; PEARSON, Alan. Systematic reviews: gatekeepers of nursing knowledge. Journal of Clinical Nursing, v. 10, n. 5, p. 593-599, 2001.

FONSECA, João José Saraiva da. Metodologia da pesquisa científica. Fortaleza: UEC, 2002. p. 78-86.

JARDIM, José Maria. Arquivos. In: CAMPELLO, Bernadete Santos; CALDEIRA, Paulo (org.). Introdução às fontes de informação. Belo Horizonte: Autêntica, 2005.

LOPES, Luiz Carlos. A gestão da informação: as organizações, os arquivos e a informática aplicada. Rio de Janeiro: Arquivo Público do Estado do Rio de Janeiro, 1996. p. 117-121.

ORTEGA, Cristina Dotta. A noção de documento: de Otlet aos dias de hoje. Pesquisa Brasileira em Ciência da Informação e Biblioteconomia, v. 5, n. 2, p. 12-32, 2010.

PONJUÁN DANTE, Glória. Gestión de la información: dimensiones e implementación para el éxito organizacional. Rosario: Nuevo Parhadigma, 2004. p. 12-18.

RONDINELLI, Rosely Curi. Gerenciamento arquivístico de documentos eletrônicos: uma abordagem teórica da diplomática arquivística contemporânea. 3. ed. Rio de Janeiro: FGV, 2005.

SANTOS, Henrique Machado Santos; FLORES, Daniel. Padronização dos formatos de arquivo: um caminho para preservar os documentos arquivísticos digitais. Biblionline, João Pessoa, v. 11, n. 1, p. 158-172, 2015. Disponível em: https://brapci.inf.br/index.php/res/download/49617. Acesso em: 20 jan. 2021.

SCHELLENBERG, Theodore Roosevelt. Arquivos modernos: Princípios e técnicas. Rio de Janeiro: FGV, 2007. p. 65-75.

TEIXEIRA, Lívia Marangon Duffles; AGANETTE, Elisângela Cristina; ALMEIDA, Maurício Barcellos. A prática arquivística e a gestão do conteúdo organizacional: relato de experiência em empresas do setor energético.

Tendências da Pesquisa Brasileira em Ciência da Informação, v. 8, n. 1, jan./jun. 2015. Disponível em: https://mba.eci.ufmg.br/downloads/181-744-1PB.pdf. Acesso em: 20 jan. 2021. 


\title{
DOCUMENT MANAGEMENT IN MINAS GERAIS STATE SCHOOLS: A SYSTEMATIC LITERATURE REVIEW
}

\begin{abstract}
Objective: To identify methodological strategies related to document management used to organize and retrieve documents in public schools in the state education system. Methodology: To this end, the Systematic Literature Review is presented as a method. Results: In the end, 53 studies were selected that showed relevance regarding the document management methodologies used for organizing and retrieving documents. Conclusions: The need for GD methodologies was identified, described in a more clear and specific way, which point out the step-by-step for the implementation of document management methodologies in institutions, since they have used informal methods, and therefore For this reason, it has structural flaws that can damage document management processes.
\end{abstract}

Descriptors: Document management. Document Management Methodology. Systematic Literature Review. Public schools.

Apêndice A - Relação dos estudos selecionados por contexto de aplicação

\begin{tabular}{|c|c|c|c|c|}
\hline Seq. & Contexto & Estudo selecionado & Ano & Autor \\
\hline 1 & \multirow{9}{*}{$\begin{array}{l}\text { Biblioteca } \\
\text { Pública }\end{array}$} & $\begin{array}{l}\text { Childrens information-retrieval behavior - a } \\
\text { case analysis of an opac }\end{array}$ & 1993 & $\begin{array}{l}\text { Solomon, } \\
\text { P. }\end{array}$ \\
\hline 2 & & $\begin{array}{l}\text { Pathways to knowledge: a perspective on } \\
\text { information and knowledge delivery in } \\
\text { Australia }\end{array}$ & 1999 & $\begin{array}{l}\text { Slack, F. } \\
\text { Rowley, J. }\end{array}$ \\
\hline 3 & & $\begin{array}{l}\text { Libraries and Knowledge Centres in the } \\
\text { Northern Territory }\end{array}$ & 2005 & $\begin{array}{l}\text { Richmond, } \\
\text { C. }\end{array}$ \\
\hline 4 & & $\begin{array}{l}\text { Projecting a Positive Image of Public Libraries } \\
\text { in Nigéria through Public Relations }\end{array}$ & 2006 & Umunna. $\mathrm{N}$. \\
\hline 5 & & $\begin{array}{l}\text { The information literacy education readiness of } \\
\text { public libraries in Mpumalanga province (South } \\
\text { Africa) }\end{array}$ & 2006 & Hart, G. \\
\hline 6 & & $\begin{array}{l}\text { Connecting } 24 / 5 \text { to Millennials: Providing } \\
\text { Academic Support Services from a Learning } \\
\text { Commons }\end{array}$ & 2009 & $\begin{array}{l}\text { Cooper, A. } \\
\text { Moore, K. }\end{array}$ \\
\hline 7 & & $\begin{array}{l}\text { Accessing the collection of a large public } \\
\text { library: an analysis of OPAC use }\end{array}$ & 2010 & Waller, V. \\
\hline 8 & & $\begin{array}{l}\text { Library experiences of hurricane katrina and } \\
\text { new orleans flood survivors. }\end{array}$ & 2010 & $\begin{array}{l}\text { Braquet, } \\
\text { D.M. }\end{array}$ \\
\hline 9 & & $\begin{array}{l}\text { Geographic information systems (gis) in public } \\
\text { library assessment }\end{array}$ & 2011 & $\begin{array}{l}\text { Bishop, B. } \\
\text { Wade, M. }\end{array}$ \\
\hline
\end{tabular}




\begin{tabular}{|c|c|c|c|c|}
\hline Seq. & Contexto & Estudo selecionado & Ano & Autor \\
\hline 10 & & $\begin{array}{l}\text { Reading Interest and Alternative Format } \\
\text { Utilisation by Persons with Visual Impairment } \\
\text { in Nigeria }\end{array}$ & 2012 & $\begin{array}{l}\text { Adetoro, N. } \\
\text { Atinmo, M.I. }\end{array}$ \\
\hline 11 & & $\begin{array}{l}\text { Exploring visual perception and children's } \\
\text { interpretations of picture books }\end{array}$ & 2012 & Yu, X.Y. \\
\hline 12 & & $\begin{array}{l}\text { Evidence Based Library and Information } \\
\text { Practice }\end{array}$ & 2015 & $\begin{array}{l}\text { Perryman, } \\
\text { C. }\end{array}$ \\
\hline 13 & & $\begin{array}{l}\text { Open Doors: library cross-sector co-operation } \\
\text { in Bristol, UK }\end{array}$ & 2015 & Chelin, J.A. \\
\hline 14 & & $\begin{array}{l}\text { The Adoption and Implementation of RFID: A } \\
\text { Literature Survey }\end{array}$ & 2016 & $\begin{array}{l}\text { Yusof, M. } \\
\text { Kamir, S. }\end{array}$ \\
\hline 15 & & $\begin{array}{l}\text { Intellectual Freedom as a Human Right: The } \\
\text { Library's Role in a Democratic Society }\end{array}$ & 2017 & Nye, V. \\
\hline 16 & & $\begin{array}{l}\text { Case Study: Dominican University School of } \\
\text { Information Studies and Skokie Public Library } \\
\text { Internship Partnership }\end{array}$ & 2017 & $\begin{array}{l}\text { Kong, R. } \\
\text { Marek, K. }\end{array}$ \\
\hline 17 & & $\begin{array}{l}\text { User-friendly libraries for active teaching and } \\
\text { learning: A case of business, technical and } \\
\text { vocational education and training colleges in } \\
\text { Uganda }\end{array}$ & 2018 & Lugya, F.K. \\
\hline 18 & & $\begin{array}{l}\text { International book donors and public libraries } \\
\text { as partners in primary school literacy } \\
\text { development in Kenya Literacy prospects and } \\
\text { obstacles }\end{array}$ & 2019 & $\begin{array}{l}\text { Mose, P. } \\
\text { Kaschula, } \\
\text { R. }\end{array}$ \\
\hline 19 & & $\begin{array}{l}\text { Status of school libraries and developmental } \\
\text { issues in Pakistan A case study of public high } \\
\text { schools }\end{array}$ & 2019 & $\begin{array}{l}\text { Tabassum, } \\
\mathrm{F}\end{array}$ \\
\hline 1 & $\begin{array}{l}\text { Biblioteca } \\
\text { Acadêmic }\end{array}$ & $\begin{array}{l}\text { Mudanças e inovações: novo modelo de } \\
\text { organização e gestão de biblioteca acadêmica }\end{array}$ & 1998 & $\begin{array}{l}\text { Andrade, } \\
\text { M.T }\end{array}$ \\
\hline 2 & & $\begin{array}{l}\text { Connecting } 24 / 5 \text { to Millennials: Providing } \\
\text { Academic Support Services from a Learning } \\
\text { Commons. }\end{array}$ & 2008 & $\begin{array}{l}\text { Moore, A.C. } \\
\text { Wells, K.A. }\end{array}$ \\
\hline 1 & $\begin{array}{l}\text { Biblioteca } \\
\text { Digital }\end{array}$ & $\begin{array}{l}\text { A digital library for education: the PEN-DOR } \\
\text { project. }\end{array}$ & 1999 & $\begin{array}{l}\text { Fullerton, K. } \\
\text { Greenberg, } \\
\text { J. }\end{array}$ \\
\hline 2 & & $\begin{array}{l}\text { Tabernacles of memory revisited: An } \\
\text { assessment of the oral history projects in } \\
\text { institutional repositories in the Pietermaritzburg } \\
\text { Cluster of Theological Libraries (PCTL), } \\
\text { KwaZulu-Natal, South África }\end{array}$ & 2016 & Garaba, F. \\
\hline
\end{tabular}




\begin{tabular}{|c|c|c|c|c|}
\hline Seq. & Contexto & Estudo selecionado & Ano & Autor \\
\hline 3 & & $\begin{array}{l}\text { Relationships Between Metadata Application } \\
\text { and Downloads in an Institutional Repository of } \\
\text { an American Law School }\end{array}$ & 2018 & $\begin{array}{l}\text { White, H C. } \\
\text { Chen, S. }\end{array}$ \\
\hline 4 & & $\begin{array}{l}\text { Proposal of a construct for information } \\
\text { management in the agent life-cycle }\end{array}$ & 2019 & $\begin{array}{l}\text { Silva, S.E. } \\
\text { Ribeiro, } \\
\text { F.N. }\end{array}$ \\
\hline 1 & \multirow[t]{6}{*}{ Hospital } & $\begin{array}{l}\text { A decentralized, community-based design for } \\
\text { statewide immunization registries in Minnesota }\end{array}$ & 1997 & $\begin{array}{l}\text { LaVenture, } \\
\text { M. Wickli } \\
\text { Schillo, T. }\end{array}$ \\
\hline 2 & & $\begin{array}{l}\text { Access to electronic health information for the } \\
\text { public: Analysis of fifty-three funded projects }\end{array}$ & 2005 & $\begin{array}{l}\text { Ruffin, A.B. } \\
\text { Cogdill, K. }\end{array}$ \\
\hline 3 & & $\begin{array}{l}\text { Blackwell Publishing Ltd The information } \\
\text { requirements and information-seeking } \\
\text { behaviours of health and social care } \\
\text { professionals providing care to children with } \\
\text { health care needs: a pilot study }\end{array}$ & 2007 & $\begin{array}{l}\text { Rachel, J, } \\
\text { Wendy, B. } \\
\text { Loretta, D. }\end{array}$ \\
\hline 4 & & $\begin{array}{l}\text { Is There Such a Thing as "Least Publishable } \\
\text { Unit"? An Empirical Investigation. }\end{array}$ & 2015 & $\begin{array}{l}\text { Budd, J.M } \\
\text { Kristine N. }\end{array}$ \\
\hline 5 & & $\begin{array}{l}\text { Family Ties: The Role of Family Context in } \\
\text { Family Health History Communication About } \\
\text { Cancer }\end{array}$ & 2016 & $\begin{array}{l}\text { Rodriguez, } \\
\text { V. }\end{array}$ \\
\hline 6 & & $\begin{array}{l}\text { Context-based interactive health information } \\
\text { searching }\end{array}$ & 2019 & $\begin{array}{l}\text { Melese; } \\
\text { Y.T. }\end{array}$ \\
\hline 1 & \multirow[t]{6}{*}{$\begin{array}{l}\text { Escola } \\
\text { Particular }\end{array}$} & $\begin{array}{l}\text { Changing Times and Requirements: } \\
\text { Implications for LIS Education }\end{array}$ & 2011 & $\begin{array}{l}\text { Chow, A.S, } \\
\text { Shaw, T.L, }\end{array}$ \\
\hline 2 & & $\begin{array}{l}\text { A educação ambiental e as políticas } \\
\text { educacionais: um estudo nas escolas públicas } \\
\text { de Teresópolis (RJ) }\end{array}$ & 2011 & $\begin{array}{l}\text { Lamosa, } \\
\text { R.A }\end{array}$ \\
\hline 3 & & $\begin{array}{l}\text { The statistics discipline in the pedagogy course } \\
\text { at USP: a historical approach }\end{array}$ & 2015 & $\begin{array}{l}\text { Ferreira, VL } \\
\text { Passos, LF }\end{array}$ \\
\hline 4 & & $\begin{array}{l}\text { A avaliação institucional como instrumento de } \\
\text { racionalização e o retorno à escola como } \\
\text { organização formal. }\end{array}$ & 2015 & Lima, LC \\
\hline 5 & & $\begin{array}{l}\text { Repercussion of the national policy in Special } \\
\text { education in the state of Espírito Santo in the } \\
\text { past ten years }\end{array}$ & 2019 & Miller, M. \\
\hline 6 & & $\begin{array}{l}\text { Does postgraduate degree make any difference } \\
\text { in job performance of information } \\
\text { professionals? }\end{array}$ & 2019 & $\begin{array}{l}\text { Hashmi, F } \\
\text { Ameen, K. }\end{array}$ \\
\hline 1 & $\begin{array}{l}\text { Escola } \\
\text { Pública }\end{array}$ & $\begin{array}{l}\text { Childrens searching behavior on browsing and } \\
\text { keyword online catalogs - the science library } \\
\text { catalog project }\end{array}$ & 1995 & $\begin{array}{l}\text { Borgman, } \\
\text { C.I. } \\
\text { Hirsh, S.G. }\end{array}$ \\
\hline
\end{tabular}




\begin{tabular}{|c|c|c|c|c|}
\hline Seq. & Contexto & Estudo selecionado & Ano & Autor \\
\hline 2 & & $\begin{array}{l}\text { National computer policy management in } \\
\text { singapore - planning an intelligent island }\end{array}$ & 1995 & Choo, C.W. \\
\hline 3 & & $\begin{array}{l}\text { Adoption of technology-mediated distance } \\
\text { education: A longitudinal analysis. }\end{array}$ & 2007 & $\begin{array}{l}\text { Ozdemir, } \\
\text { Z.D. }\end{array}$ \\
\hline 4 & & $\begin{array}{l}\text { Business intelligence as supporting technology } \\
\text { for strategy definition to the improvement of } \\
\text { teaching quality. }\end{array}$ & 2010 & $\begin{array}{l}\text { Reis, E.S. } \\
\text { Angeloni, } \\
\text { M.T. }\end{array}$ \\
\hline 5 & & $\begin{array}{l}\text { The use of Social Networking Sites (SNSs) by } \\
\text { the faculty members of the School of Library \& } \\
\text { Information Science, PAAET, Kuwait }\end{array}$ & 2015 & $\begin{array}{l}\text { Mansour, } \\
\text { E.A }\end{array}$ \\
\hline 6 & & $\begin{array}{l}\text { "Beginning a Journey of knowledge } \\
\text { Management in a Secondary School" }\end{array}$ & 2016 & Chu, K.W \\
\hline 1 & $\begin{array}{l}\text { Universid } \\
\text { ade }\end{array}$ & $\begin{array}{l}\text { Building a Strong Web: Connecting Information } \\
\text { Spaces in Schools and Communities }\end{array}$ & 2009 & $\begin{array}{l}\text { Ritzo, C. } \\
\text { Nam, C. }\end{array}$ \\
\hline 2 & & $\begin{array}{l}\text { The JISC Academic Database Assessment } \\
\text { Tool - virtues and vices }\end{array}$ & 2010 & Jacso, $P$. \\
\hline 3 & & $\begin{array}{l}\text { Exploration of usage behavioral model } \\
\text { construction for university library electronic } \\
\text { resources }\end{array}$ & 2015 & $\begin{array}{l}\text { Chang, S.S. } \\
\text { Lou, S.J. }\end{array}$ \\
\hline 1 & $\begin{array}{l}\text { Redes } \\
\text { Sociais }\end{array}$ & $\begin{array}{l}\text { Internet search approaches: The influence of } \\
\text { age, search goals, and experience }\end{array}$ & 2003 & Slone, D.J. \\
\hline 2 & & $\begin{array}{l}\text { The visibility of health web portals for teens: a } \\
\text { hyperlink analysis. }\end{array}$ & 2011 & $\begin{array}{l}\text { Bowler, L. } \\
\text { Hong, W.Y. }\end{array}$ \\
\hline 3 & & $\begin{array}{l}\text { Issues in Information Behaviour on Social } \\
\text { Media }\end{array}$ & 2014 & $\begin{array}{l}\text { Khoo, } \\
\text { C.S.G. }\end{array}$ \\
\hline 4 & & $\begin{array}{l}\text { IT Professionals' Information Behaviour on } \\
\text { Twitter }\end{array}$ & 2015 & Talip, B. A. \\
\hline 5 & & $\begin{array}{l}\text { Modeling Successful Performance in Web } \\
\text { Searching }\end{array}$ & 2015 & $\begin{array}{l}\text { Aula, A. } \\
\text { Klaus, N. }\end{array}$ \\
\hline 1 & $\begin{array}{l}\text { Empresa } \\
\text { Privada }\end{array}$ & $\begin{array}{l}\text { Employee Perception of the Knowledge } \\
\text { Sharing Culture in Kuwait Companies: Effect of } \\
\text { Demographic Characteristics }\end{array}$ & 2015 & Marouf, L. \\
\hline 1 & $\begin{array}{l}\text { Arquivo } \\
\text { Pessoal }\end{array}$ & $\begin{array}{l}\text { Medium Rare: Exploring Archives and Their } \\
\text { Conversion from Original to Digital Part Two- } \\
\text { The HolisticKnowledge Arsenal of Paper-based } \\
\text { Archives. }\end{array}$ & 2011 & $\begin{array}{l}\text { Latham, K. } \\
\text { F. }\end{array}$ \\
\hline 53 & \multicolumn{4}{|c|}{ TOTAL } \\
\hline
\end{tabular}

Fonte: Araújo e Aganette (2021) 
Recebido em: 27.05.2021

Aceito em: 17.12.2021 